\title{
Kidney and Ureter
}

National Cancer Institute

\section{Source}

National Cancer Institute. Kidney and Ureter. NCI Thesaurus. Code C61107.

Part of the upper urinary tract located in the retroperitoneum. The kidneys are the functional unit of the urinary system producing urine, which is transported from the renal pelvis of each kidney to the urinary bladder by the ipsilateral ureter. 